\title{
Comparison of haemodynamic responses to dobutamine and salbutamol in cardiogenic shock after acute myocardial infarction
}

\author{
M B FOWLER, A D TIMMIS, J P CRICK, R VINCENT, D A CHAMBERLAIN
}

\begin{abstract}
Nine patients with critically reduced cardiac output after acute myocardial infarction underwent a single cross-over comparison of dobutamine and salbutamol to compare the haemodynamic effects of these drugs, which have, respectively, predominantly beta $a_{1}$-adrenergic and beta $a_{2}$-adrenergic agonist activity. The responses were used to select the more appropriate treatment for individual patients. Only relatively small responses were obtained: those with the poorest baseline measurements tended to show the least effect.

When the results from the series were averaged, dobutamine (250-750 $\mu \mathrm{g} / \mathrm{min})$ caused a small but progressive increase in cardiac index $\left(1.8\right.$ to $\left.2.21 / \mathrm{min} / \mathrm{m}^{2}\right)$ throughout the dose range. Systemic blood pressure was not increased, and calculated systemic vascular resistance fell from 25 to 19 units. Heart rate rose from 107 to 118 beats $/ \mathrm{min}$ and stroke index from 17 to $19 \mathrm{ml} /$ beat $/ \mathrm{m}^{2}$. Pulmonary artery end-diastolic pressure fell from 18 to 15 mm Hg.

Salbutamol (10-40 $\mu \mathrm{g} / \mathrm{min})$ produced a similar progressive increase in cardiac index, from 1.6 to $2 \cdot 21 / \mathrm{min} / \mathrm{m}^{2}$. Systemic blood pressure was not altered, and systemic vascular resistance fell from 25 to 20 units. Heart rate rose from 105 to 119 beats/min and stroke index from 16 to $19 \mathrm{ml} / \mathrm{beat} / \mathrm{m}^{2}$. Pulmonary artery end-diastolic pressure did not fall.

Dobutamine and salbutamol have closely similar haemodynamic effects when used in cardiogenic shock
\end{abstract}

Royal Sussex County Hospital, Brighton BN2 5BE

M B FOWLER, MB, MRCP, cardiac registrar (present address: Department of Cardiology, King's College Hospital, London SE5)

A D TIMMIS, MB, MRCP, cardiac registrar (present address: Department of Cardiology, Massachusetts General Hospital, Boston)

J P CRICK, MB, MRCP, research registrar (present address: Department of Cardiology, Guy's Hospital, London)

$R$ VINCENT, MB, MRCP, consultant cardiologist

D A CHAMBERLAIN, MD, FRCP, consultant cardiologist after acute myocardial infarction. Both drugs increase cardiac index but heart rate also rises, and the increase in stroke index is relatively small. Mean arterial pressure is altered little by either agent, but dobutamine (in contrast with dopamine) tends to reduce pulmonary artery end-diastolic pressure, which may be beneficial.

\section{Introduction}

Dobutamine is thought to be a relatively specific beta ${ }_{1}^{-}$ adrenergic agonist. ${ }^{2}$ It increases cardiac output and reduces left ventricular filling pressure after acute myocardial infarction ${ }^{3} 4$ and in chronic heart failure, ${ }^{56}$ probably through a direct action on myocardial contractility. Salbutamol is a relatively specific beta $a_{2}$-adrenergic receptor agonist which also counters lowoutput states after acute myocardial infarction but principally through arteriolar dilatation rather than a direct action on myocardial contractility. ${ }^{78}$ In cardiogenic shock we find it free from the disadvantage of increasing peripheral vascular resistance or greatly increasing heart rate. ${ }^{9}$

Dobutamine is also free of these effects in chronic heart failure and is recommended for treating acute myocardial infarction complicated by left ventricular failure. ${ }^{3}$ The effects of dobutamine, however, have not been reported in patients acutely ill with cardiogenic shock after acute myocardial infarction: in such cases its actions may differ slightly from those predicted by studies under less severe conditions.

While selecting the optimal treatment for individual patients with critically reduced cardiac output after acute myocardial infarction we took the opportunity to compare the principal haemodynamic effects of dobutamine and salbutamol, as there are no reported comparisons of these two drugs under conditions of cardiogenic shock which could be used as a guide to treatment.

\section{Patients and methods}

We studied 14 patients (eight men, six women) with cardiogenic shock after acute myocardial infarction. Their ages ranged from 52 to 75 years (mean 64). Infarction was anterior in eight patients, 
inferior in two, and anterior and inferior in two. The site could not be determined in two patients because the electrocardiographic pattern was obscured by left bundle-branch block. The only patient not in sinus rhythm had complete atrioventricular block and was paced with atrial synchronisation (atrioventricular delay $100 \mathrm{~ms}$ ).

All the patients had clinical evidence of low cardiac output with cold, clammy skin and a urine output of less than $20 \mathrm{ml} /$ hour. Twelve of the 14 had systolic hypotension (systolic pressure less than 100 $\mathrm{mm} \mathrm{Hg}$ ). All had radiographic evidence of pulmonary oedema, and none had had a diuresis in response to intravenous frusemide. Two had received intravenous digoxin and one ouabain. All the patients were sedated with opiates but had failed to show any response to other conventional measures.

A single cross-over trial design was used to compare the haemodynamic effects of dobutamine and salbutamol. Paired random numbers were used to select which drug should be given first: provision was made for withdrawal if a definite improvement occurred before the comparison was complete. No patient was withdrawn for this reason but four died before the comparison, and in one the pulmonary artery pressure was so high that we had to depart from the study protocol and infuse vasodilators. The remaining nine patients were given infusions of both drugs. Although the withdrawal and deaths interfered with randomisation, five patients received dobutamine first and four salbutamol first. The drugs were diluted in 5\% dextrose and administered into a central vein using an IVAC drip controller with infusion rates of 250,500 , and $750 \mu \mathrm{g}$ dobutamine $/ \mathrm{min}$ and 10,20 , and $40 \mu \mathrm{g} \mathrm{salbutamol} / \mathrm{min}$.

Measurements were made before starting the drug infusion and 20 minutes after each dose increment. In every case the infusion was stopped for 30 minutes and the haemodynamic measurements repeated before the second drug infusion was started. We had intended to discontinue the second drug infusion at the end of the study and repeat the haemodynamic measurements, but three patients (two receiving salbutamol, and one dobutamine) were too ill to permit withdrawal of supportive treatment for a second time. At the end of the study, treatment was continued with the drug judged to produce the better haemodynamic effect.

Cardiac output and radial artery and right heart pressures were measured as described, ${ }^{7}$ except that a thermodilution injector gun (OMP Laboratories Inc, model 3700) was used to inject $10 \mathrm{ml} \mathrm{5 \%}$ dextrose at room temperature. Cardiac output measurements were made in replicate sets of five. The mean variation for the sets was $0.25 \mathrm{l} / \mathrm{min}$ after rejection of a few solitary, grossly deviant readings.

Peripheral resistance was calculated in arbitrary units as mean arterial pressure in $\mathrm{mm} \mathrm{Hg}$ divided by cardiac output in $1 / \mathrm{min}$. Stroke work index $\left(\mathrm{g}-\mathrm{m} / \mathrm{m}^{2}\right)$ was calculated as the difference between mean arterial pressure and pulmonary artery end-diastolic pressure in $\mathrm{mm} \mathrm{Hg}$ multiplied by stroke index $\left(\mathrm{ml} / \mathrm{beat} / \mathrm{m}^{2}\right)$ multiplied by 0.0144 .

- The patients had their bladders catheterised routinely, and urine volumes were measured during each infusion period.

The reason for the infusions and observations was explained to the patients. We did not, however, seek formal consent, as we thought that this would unnecessarily heighten anxiety during measurements which were performed primarily as a guide to management. The protocol was accepted by the hospital ethical committee. Student's paired $t$ test was used for statistical comparisons.

\section{Results}

Tables I and II list the principal haemodynamic effects of dobutamine and salbutamol in the nine patients who received both drugs, and figs 1 and 2 show the dose-response curves.

The haemodynamic response to the two drugs was similar. Both progressively increased cardiac index throughout the dose range and caused significant increases in heart rate $(p<0.01)$. The principal difference between the two drugs was their effect on pulmonary artery end-diastolic pressure. A progressive fall, from 18 to $15 \mathrm{~mm} \mathrm{Hg}$, was observed only with dobutamine. This difference was significant $(p<0.02)$ at maximum dosage.

No difference in urine output was detected during treatment with the two drugs, but only five of the patients responded with an output exceeding $20 \mathrm{ml} /$ hour. One patient had a diuresis which began when the first drug (salbutamol) was infused and which continued throughout the study.

All patients who showed little or no haemodynamic benefit from treatment had a poor short-term prognosis. Figure 3 shows the response in two groups: those who died in less than five days, and those who survived five days or more. The poor responders also tended to be those with the most critical haemodynamic disturbance initially. Thirteen of our patients were in the very-high-risk group characterised as having a hospital mortality of $80 \%{ }^{10}$ Though five patients survived five days or more only three left hospital alive.

TABLE I-Haemodynamic effects of dobutamine in cardiogenic shock in nine patients. Values are means $\pm S E M$

\begin{tabular}{|c|c|c|c|c|}
\hline & Control & $\begin{array}{l}\text { Dobutamine } \\
250 \mu \mathrm{g} / \mathrm{min}\end{array}$ & $\begin{array}{l}\text { Dobutamine } \\
500 \mu \mathrm{g} / \mathrm{min}\end{array}$ & $\begin{array}{l}\text { Dobutamine } \\
750 \mu \mathrm{g} / \mathrm{min}\end{array}$ \\
\hline $\begin{array}{l}\text { Cardiac index }\left(1 / \mathrm{min} / \mathrm{m}^{2}\right) \quad \ldots \\
\text { Heart rate }(\text { beats } / \mathrm{min}) \\
\text { Systolic blood pressure (mm }\end{array}$ & $\begin{array}{l}1 \cdot 8 \pm 0 \cdot 1 \\
107 \pm 5\end{array}$ & $\begin{array}{l}2 \cdot 1 \pm 0 \cdot 1^{* *} \\
112 \pm 6\end{array}$ & $\begin{array}{l}2 \cdot 1 \pm 0 \cdot 1 * * \\
114 \pm 5^{* * *}\end{array}$ & $\begin{array}{l}2 \cdot 2 \pm 0 \cdot 1 * * \\
118 \pm 6^{* * *}\end{array}$ \\
\hline $\begin{array}{l}\text { Hg) } \\
\text { Diastolic blood pressure }\end{array}$ & $97 \pm 5$ & $98 \pm 6$ & $96 \pm 5$ & $95 \pm 5$ \\
\hline $\begin{array}{l}(\mathrm{mm} \mathrm{Hg}) \\
\text { Mean blood pressure (mm }\end{array}$ & $56 \pm 2$ & $58 \pm 2$ & $56 \pm 2$ & $55 \pm 2$ \\
\hline $\begin{array}{l}\mathrm{Hg} \text { ) } \\
\text { Right atrial pressure (mm }\end{array}$ & $71 \pm 3$ & $71 \pm 4$ & $68 \pm 3$ & $67 \pm 3$ \\
\hline $\begin{array}{l}\mathrm{Hg} \text { ) } \\
\text { Pulmonary artery end-dia- }\end{array}$ & $4 \pm 1$ & $2 \pm 1$ & $2 \pm 1$ & $2 \pm 1$ \\
\hline $\begin{array}{l}\text { Puimonary artery end-dia- } \\
\text { stolic pressure (mm Hg }) \\
\text { Systemic vascular resistance }\end{array}$ & $18 \pm 2$ & $17 \pm 2$ & $16 \pm 2$ & $15 \pm 2^{* *}$ \\
\hline $\begin{array}{l}\text { (units) } 0 \\
\text { Stroke volume index (mil/ }\end{array}$ & $25 \pm 1$ & $21 \pm 1 * *$ & $20 \pm 2 * *$ & $19 \pm 1^{* *}$ \\
\hline $\begin{array}{l}\left.\text { beat } / \mathrm{m}^{2}\right) \\
\text { Stroke work index } \ddot{\left(\mathrm{g}-\mathrm{m} / \mathrm{m}^{2}\right)}\end{array}$ & $\begin{array}{l}17 \pm 2 \\
12 \pm 2\end{array}$ & $\begin{array}{l}19 \pm 2 * \\
15 \pm 2\end{array}$ & $\begin{array}{l}19 \pm 2 * \\
14 \pm 2\end{array}$ & $\begin{array}{l}19 \pm 2 * \\
14 \pm 2\end{array}$ \\
\hline
\end{tabular}

Reference point for pressure was sternal angle (add $5 \mathrm{~mm} \mathrm{Hg}$ to equate with midchest readings).
Comparison with control values: ${ }^{*} \mathrm{p}<0.05 ;{ }^{* *} \mathrm{p}<0.02 ;{ }^{* * *} \mathrm{p}<0.01$.

TABLE II-Haemodynamic effects of salbutamol in cardiogenic shock in nine patients. Values are means $\pm S E M$

\begin{tabular}{|c|c|c|c|c|}
\hline & Control & $\begin{array}{l}\text { Salbutamol } \\
10 \mu \mathrm{g} / \mathrm{min}\end{array}$ & $\begin{array}{l}\text { Salbutamol } \\
20 \mu \mathrm{g} / \mathrm{min}\end{array}$ & $\begin{array}{l}\text { Salbutamol } \\
40 \mu \mathrm{g} / \mathrm{min}\end{array}$ \\
\hline $\begin{array}{l}\text { Cardiac index }\left(1 / \mathrm{min} / \mathrm{m}^{2}\right) \quad \ldots \\
\text { Heart rate }(\text { beats } / \mathrm{min})\end{array}$ & $\begin{array}{l}1 \cdot 6 \pm 0 \cdot 18 \\
105 \pm 6\end{array}$ & $\begin{array}{l}1 \cdot 7 \pm 0 \cdot 1 \\
109 \pm 5\end{array}$ & $\begin{array}{l}2 \cdot 0 \pm 0 \cdot 1^{* * *} \\
113 \pm 5\end{array}$ & $\begin{array}{l}2 \cdot 2 \pm 0 \cdot 2 * * * * \\
119 \pm 6^{* * *}\end{array}$ \\
\hline $\begin{array}{l}\text { Systolic blood pressure }(\mathrm{mm} \\
\text { Hg) } \\
\text { Diastolic blood } \quad \text { pressure }\end{array}$ & $92 \pm 6$ & $92 \pm 4$ & $93 \pm 4$ & $94 \pm 5$ \\
\hline $\begin{array}{l}\text { (mm Hg). } \\
\text { Mean blood pressure }(\mathrm{mm}\end{array}$ & $56 \pm 2$ & $56 \pm 2$ & $56 \pm 2$ & $56 \pm 1$ \\
\hline $\begin{array}{c}\mathrm{Hg} \text { ) } \\
\text { Right atrial pressure (mm }\end{array}$ & $67 \pm 3$ & $68 \pm 2$ & $68 \pm 2$ & $66 \pm 2$ \\
\hline $\begin{array}{l}\mathrm{Hg} \text { ) } \\
\text { Pulmonary artery end-dia- }\end{array}$ & $4 \pm 1$ & $3 \pm 1$ & $4 \pm 1$ & $4 \pm 1$ \\
\hline $\begin{array}{l}\text { Pulmonary artery end-dia- } \\
\text { stolic pressure (mm Hg) } \\
\text { Systemic vascular resistance }\end{array}$ & $18 \pm 1$ & $18 \pm 1$ & $19 \pm 2$ & $19 \pm 1$ \\
\hline $\begin{array}{l}\text { (units) } \\
\text { Stroke volume index (mil) }\end{array}$ & $25 \pm 2$ & $24 \pm 2$ & $21 \pm 1 * * *$ & $20 \pm 2 * * *$ \\
\hline $\begin{array}{l}\left.\text { beat } / \mathrm{m}^{2}\right) \\
\text { Stroke work index }\left(\ddot{g}-\mathrm{m} / \mathrm{m}^{2}\right)\end{array}$ & $\begin{array}{l}16 \pm 2 \\
11 \pm 2\end{array}$ & $\begin{array}{l}17 \pm 2 \\
12 \pm 2\end{array}$ & $\begin{array}{l}19 \pm 2 \\
13 \pm 2\end{array}$ & $\begin{array}{l}19 \pm 2 \\
13 \pm 2\end{array}$ \\
\hline
\end{tabular}

Reference point for pressure was sternal angle (add $5 \mathrm{~mm} \mathrm{Hg}$ to equate with midchest

readings).
Comparison with control values: ${ }^{*} \mathrm{p}<0.05 ;{ }^{* *} \mathrm{p}<0.02 ;{ }^{* *} \mathrm{p}<0.01$.

\section{Discussion}

Cardiogenic shock after acute myocardial infarction remains a major therapeutic problem. The mortality is determined $₹$ principally by the extent of muscle damage and can be altered $ᄋ$ only marginally by any drug intervention. The prognosis in a $N$ small group of patients may be improved if the vicious circle of deteriorating left ventricular function leading to extension of infarction can be broken.

There is increasing evidence that the amount of muscle loss

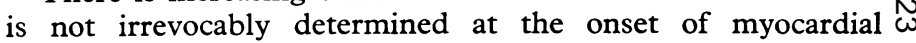
infarction. ${ }^{11}{ }^{12}$ The principal goal of drug treatment in cardiogenic shock is to improve left ventricular performance without 0 increasing oxygen demand to a degree that might jeopardise the viability of the ischaemic zone.

Salbutamol exerts its beneficial effect principally by arteriolar $\frac{T}{0}$ dilatation, which must have little metabolic cost to the heart. Though dobutamine does increase myocardial contractility, its $\frac{?}{1}$

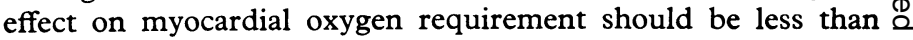
that of other beta $_{1}$ agonists, since it reportedly causes little acceleration of heart rate. ${ }^{1}$ Both drugs therefore have a possible 8 role in augmenting cardiac output in myocardial infarction despite their dissimilar pharmacological actions in stimulating beta ${ }_{1}$-adrenergic and beta $_{2}$-adrenergic receptors. 


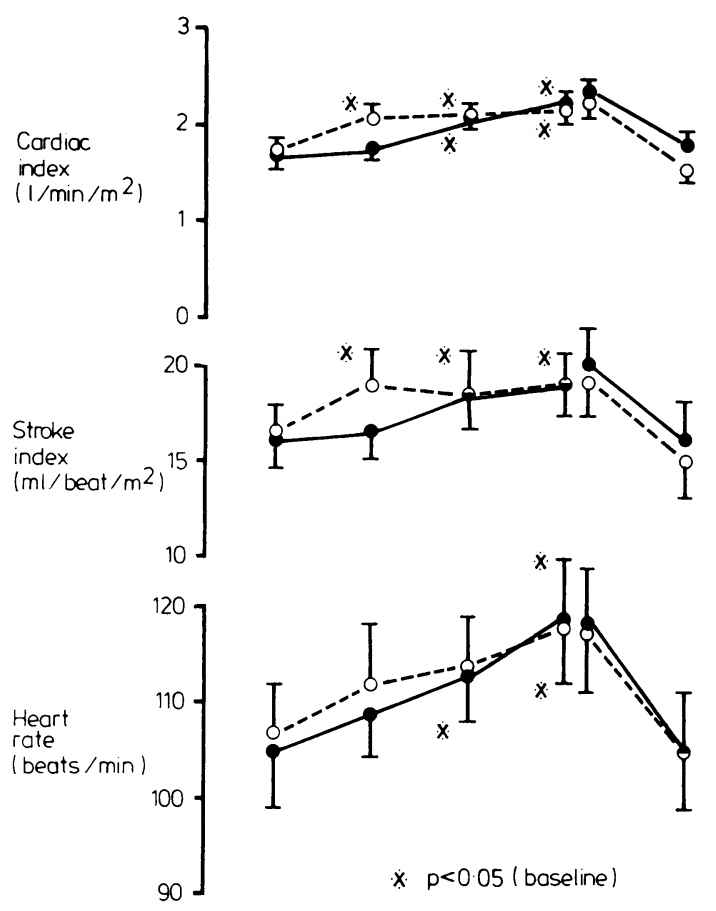

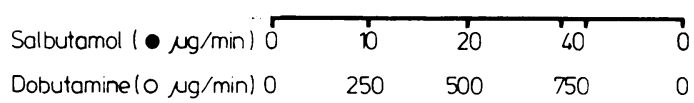

FIG 1-Effect on cardiac index, stroke index, and heart rate of dobutamine and salbutamol infusions before and during treatment in nine patients, and after stopping treatment in six. Values are means $\pm S E M$. Reference point for pressure was sternal angle (add $5 \mathrm{~mm} \mathrm{Hg}$ to equate with midchest values).
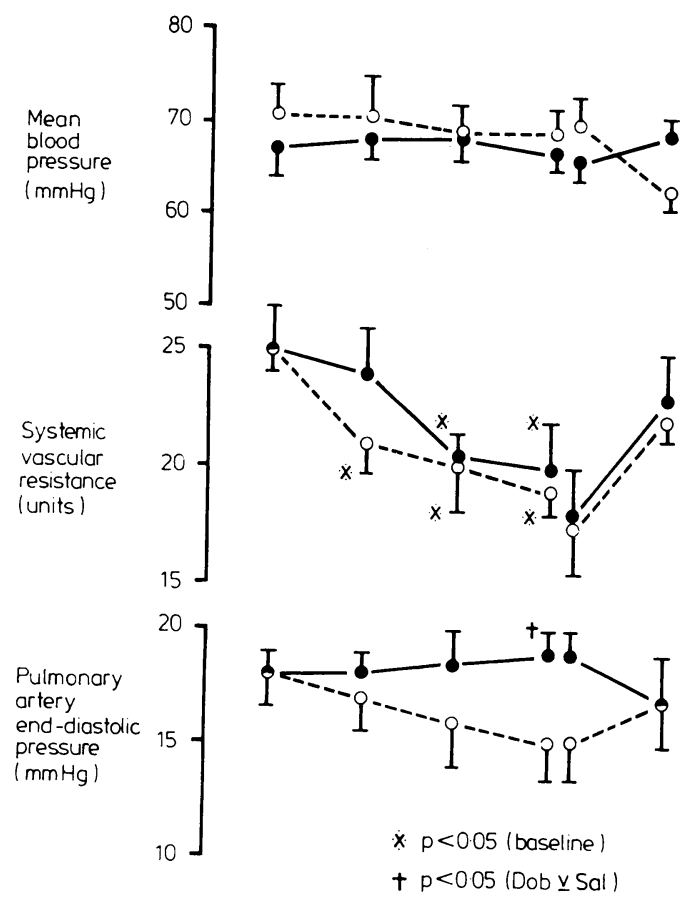

\begin{tabular}{|c|c|c|c|}
\hline Salbutamol $(\bullet \mu \mathrm{g} / \mathrm{min}) 0$ & 10 & 20 & $40^{1}$ \\
\hline Dobutamine $(0 \mathrm{\mu g} / \mathrm{min}) 0$ & 250 & 500 & 750 \\
\hline
\end{tabular}

FIG 2-Effect on mean blood pressure, systemic vascular resistance, and pulmonary artery end-diastolic pressure of dobutamine and salbutamol infusions before and during treatment in nine patients, and after stopping treatment in six. Values are means \pm SEM. Reference point for pressure was sternal angle (add $5 \mathrm{~mm} \mathrm{Hg}$ to equate with midchest values).
Our results show that the haemodynamic improvement with either agent tends to be small and that despite their contrasting sites of action dobutamine and salbutamol produce remarkably similar haemodynamic effects. Both modestly augment cardiac output without increasing systemic blood pressure; calculated peripheral resistance therefore falls. Both drugs increase heart rate, especially at higher doses, but to a less extent than would be expected with dopamine or isoprenaline. ${ }^{1}$ The principal difference between the two agents concerns left ventricular filling pressure, which dobutamine alone tends to reduce. In our series, however, this effect was considerably smaller than reported in a less severely ill group of patients. ${ }^{4}$

Unlike other published studies on the effect of dobutamine in myocardial infarction, ${ }^{34}$ our observations were made during treatment of patients with critical cardiogenic shock. The

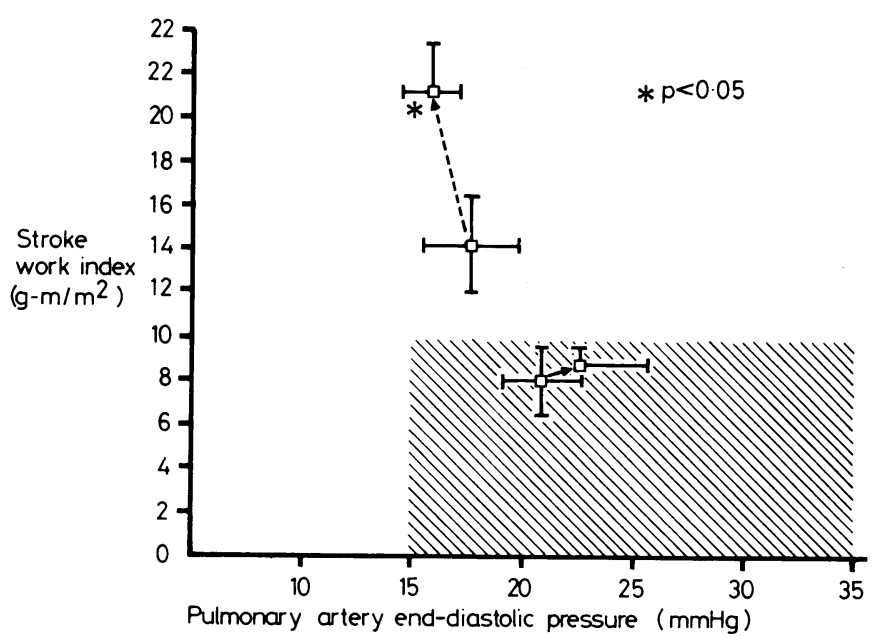

FIG 3-Effect of treatment on pulmonary artery end-diastolic pressure and stroke work index in 13 patients originally entered into trial. Five patients who survived for over five days $(\square--\rightarrow \square)$ shown separately from eight patients who died in under five days $(\square--\rightarrow \square)$. Values (means \pm SEM) are at entry and during more favourable response to treatment (in eight cases with dobutamine and five with salbutamol). Shaded area indicates haemodynamic variables associated with extreme risk as defined by Chatterjee and $\operatorname{Swan}^{10}$ (see text)

responses cannot be predicted from data collected under other conditions. We find that infusions of dopamine (at over 500 $\mu \mathrm{g} / \mathrm{min}$ ) in patients with cardiogenic shock cause considerable increase in left atrial pressure, ${ }^{9}$ presumably reflecting worsening heart failure in response to increased peripheral resistance-a noradrenaline-like (alpha-adrenergic) effect. Dobutamine is free from this effect: the progressive fall in filling pressure with higher doses presumably reflects the inotropic effect of the drug rather than venodilatation. The relatively slight chronotropic effect in comparison with the action augmenting contractility is unique to dobutamine among the beta ${ }_{1}$-adrenergic agonists. ${ }^{1}$

As with our studies on dopamine, ${ }^{9}$ the long-term survival rate was disappointing. Drug treatment in established cardiac shock may rescue a few patients, but usually only delays deathof value in the presence of complications amenable to openheart surgery or if prospects of salvaging severely ischaemic myocardium come to fruition. ${ }^{13}$ Vasodilator and inotropic treatment should also be used as necessary to prevent the vicious circle of deteriorating left ventricular function leading to extension of infarction and may be of greatest value when used before cardiogenic shock becomes established. (We have already confirmed that dopamine has serious disadvantages when used as an inotropic agent in the presence of severe myocardial dysfunction after infarction. $)^{9}$

We believe that both salbutamol and dobutamine are pre- 
ferable in such cases. Salbutamol may be the more appropriate if filling pressure is not raised to a degree which causes intractable pulmonary oedema, because its dominantly peripheral action should spare myocardial oxygen requirements and therefore does not threaten jeopardised myocardium. Dobutamine may be more useful if reduction of left ventricular filling pressure is an urgent necessity which overrides possible metabolic consequences.

\section{Requests for reprints should be sent to Dr D A Chamberlain.}

\section{References}

1 Tuttle RR, Mills J. Dobutamine: development of a new catecholamine to selectively increase cardiac contractility. Circ Res 1975 ;36:185-96.

2 Jewitt D, Birkhead J, Mitchell A, Dollery C. Clinical cardiovascular pharmacology of dobutamine, a selective inotropic catecholamine. Lancet 1974 ;ii:363-7.

${ }^{3}$ Gillespie TA, Ambos HD, Sobel BE, Roberts R. Effects of dobutamine in patients with acute myocardial infarction. Am $\mathcal{F}$ Cardiol 1977;39: 588-94.

${ }^{4}$ Goldstein RA, Passamani ER, Roberts R. A comparison of digoxin and dobutamine in patients with acute infarction and cardiac failure. N Engl f Med $1980 ; 303: 846-50$.

5 Stoner JD, Bolen JL, Harrison DC. Comparison of dobutamine and dopamine in treatment of severe heart failure. Br Heart $\mathcal{F} 1977$;39:536-9.

${ }^{6}$ Leier CV, Heban PT, Huss P, Bush CA, Lewis RP. Comparative systemic and regional hemodynamic effects of dopamine and dobutamine in patients with cardiomyopathic heart failure. Circulation 1978;58:466-75.

${ }^{7}$ Timmis AD, Strak SK, Chamberlain DA. Haemodynamic effects of salbutamol in patients with myocardial infarction and severe left ventricular dysfunction. Br Med F 1979;ii:1101-3.

${ }^{8}$ Dawson JR, Poole-Wilson PA, Sutton GC. Salbutamol in cardiogenic shock complicating acute myocardial infarction. Br Heart $\mathcal{f} 1980 ; 43$ : 522-6.

9 Timmis AD, Fowler MB, Chamberlain DA. Comparison of haemodynamic responses to dopamine and salbutamol in severe cardiogenic shock complicating acute myocardial infarction. Br Med f 1981 ;282:7-9.

${ }^{10}$ Chatterjee K, Swan HJC. Hemodynamic profile in acute myocardial infarction. In: Corday E, Swan $\mathrm{HJC}$, eds. Myocardial infarction. Baltimore: Williams and Wilkins, 1973:51-61.

11 Yusuf S, Ramsdale D, Peto R, et al. Early intravenous atenolol treatment in suspected acute myocardial infarction. Lancet 1980 ;ii:273-6.

12 Norris RM. Beta adrenoceptor blockade in acute myocardial infarction. Am Heart f 1980;99:683-5.

${ }^{13}$ Leinbach RC, Gold HK. Regional streptokinase in myocardial infarction. Circulation $1981 ; 63: 498-9$.

(Accepted 28 September 1981)
ONE HUNDRED YEARS AGO The winter session of the Army Medical School, at Netley, was concluded on February 6th. The prizes were delivered to the successful competitors by Field Marshal HRH the Duke of Cambridge, who left London by an early train, travelling by the London and South Western railway for the purpose. On reaching Netley the Duke was received by HSH Prince Edward of Saxe Weimar, commanding the southern district, and staff, together with the military and medical officers of the Royal Victoria Hospital, and professors of the Army Medical School. The surgeons on probation, and a number of visitors, were assembled in the principal lecture room. Some ladies, including the Princess of Saxe Weimar, were also present on the occasion. As soon as His Royal Highness and staff had taken their seats in the lectureroom, a report was read by Professor Longmore on the results of the session; and the names of the gentlemen who had gained the prizes were announced. An account was also read of a new distinction which has been recently added to those previously in the gift of the school, viz, a prize which has been opened for competition in the department of military surgery, and for which the school is indebted to the liberality of $\mathrm{Mr}$ Nathaniel Montefiore, FRCS.

On the preliminary business being concluded, the Duke of Cambridge handed the prizes successively to the gentlemen who had won them, and then addressed the army surgeons on probation in a speech of considerable length and interest. His remarks were highly complimentary to the officers of the military medical services. After some general observations on the progress of the Army Medical School and the instruction given in it, His Royal Highness spoke as follows. "The work done by the medical officers in Afghanistan and South Africa within the last two years, under the directions of Surgeons-General Ker Innes and Holloway, has been brought prominently to my notice in various reports which have been laid before me. I have not been able to put my finger on any defect in the working of the department, and the manner in which the medical and surgical duties have been discharged by the army surgeons affords good evidence of the value of the instruction which has been given to them at this school. It has not been only in their purely professional duties that the medical officers have distinguished themselves in recent campaigns, but they have also been conspicuous for their gallantry in the field. I may refer especially to the circumstance that, in the unfortunate affair at Majuba Hill, an episode in our annals on which it is not pleasant to dwell, two young medical officers who had not long before passed through Netley remained to share the fortunes of the wounded committed to their care, and both fell honourably at their posts. I am aware, too, that it is not only in time of war that army medical officers are called upon to risk their lives; they often do so in time of peace, on the occasions of epidemics of disease in various climates. It is not long since four medical officers fell victims to yellow fever, while contending with the disease in Barbadoes. Such sacrifices, when nobly made at the call of duty, confer honour on the whole medical department." His Royal Highness then particularly called the attention of the young surgeons to their important duties and responsibilities, urging them to remember that everyone wearing Her Majesty's uniform lives, as it were, in public, and is bound, therefore, to be specially circumspect in conduct. He remarked that, under the new system, medical officers in their early periods of service are more free from control than they have ever been, and that there is, in consequence, all the more need for them to be doubly cautious on every point of duty. He also alluded to the fact that messes are being introduced at the larger stations for medical officers, and that he hoped great advantage would result to them from the arrangement. After a few further remarks, His Royal Highness expressed himself highly gratified at the fact that all the surgeons on probation who had just gone through the course of instruction at the school had gained their commissions, and heartily congratulated those among them who had carried off the prizes; concluding by wishing them all an honourable and pleasant career in the respective branches of the public service which they were on the eve of entering.

Luncheon was afterwards served, in the officers' mess-room, to the Duke of Cambridge and other distinguished visitors. Although a dense fog was prevailing at the time His Royal Highness left London, the day turned out to be bright and clear, and almost as mild as a day in spring, on arriving at Netley. The Duke left by an afternoon train to return to London. (British Medical fournal, 1882.) 